\title{
Opioid Analgesics in Primary Care: Challenges and New Advances in the Management of Noncancer Pain
}

\author{
Raymond Sinatra, $M D, P h D$
}

\begin{abstract}
Primary care attitudes affecting the use of strong opioids in pain management have changed considerably in the last 3 decades. Forces that have shaped current attitudes and trends in opioid prescribing include historical influences, regulatory factors, and technologic and scientific advances. The article identifies for primary care physicians the current challenges and issues surrounding the use of opioid analgesics for noncancer pain and examines how new technology and expanding knowledge have been applied to existing opioids such as morphine, oxymorphone, and fentanyl to address continuing challenges in pain management. (J Am Board Fam Med 2006;19:165-77.)
\end{abstract}

Chronic pain is a widespread and challenging problem for primary care physicians and family physicians, particularly in patients with nonmalignant pain syndromes, who represent a growing proportion of chronic pain diagnoses. ${ }^{1}$ For patients with moderate to severe acute or chronic pain, nonopioid analgesics may not be sufficient to achieve adequate analgesia. Historically, the use of opioids to manage pain has oscillated from broad indiscriminate use a century ago to narrowly restricted use in subsequent decades that left too many people without adequate analgesia. More recently, multiple forces have driven the increased use of strong opioids in the management of pain, including an evolving regulatory outlook and increasing acceptance from the clinical community. ${ }^{2,3}$ National legislation recognizing the importance of pain treatment has been proposed, including an effort to establish a National Center for Pain and Palliative Care Research. The Agency for Health Care Policy and Research has established pain treatment guidelines, and the Joint Commission on Accreditation

Submitted 20 December 2004; accepted 22 November 2005. CT

From Yale University School of Medicine, New Haven,

Conflict of interest: RS claims no direct or indirect financial incentive associated with this article.

Corresponding author: Raymond Sinatra, MD, PhD, Professor of Anesthesiology, Director, Pain Management Service, Department of Anesthesiology, Yale University School of Medicine, New Haven, CT 06510 (E-mail: raymond.sinatra@yale.edu). of Healthcare Organizations has included pain treatment in its evaluation of hospitals and healthcare providers. Reports on advances in pain research in consumer media are increasing the overall understanding of the importance of treating pain. The net result of these factors has been an increased use of strong opioids by nonspecialists for the management of chronic moderate to severe pain.

The movement to treat chronic pain with strong opioids first gained acceptance in the treatment of pain associated with cancer, for which concerns about addiction and abuse were believed to be minimal. ${ }^{4}$ Experience in treating chronic cancer-related pain suggested that other forms of severe, chronic pain could be safely treated in the long term with opioid medications. ${ }^{5,6}$ As a result, opioids have become a mainstay for reliably treating moderate to severe nociceptive pain, ${ }^{7,8}$ defined as a physiologic response to neural inflammation produced by tissue damage from noxious stimuli. Some specific sources include osteoarthritis, lower back injuries or conditions, and postsurgical trauma.

The expanding use of opioids is also influenced by cost issues. The annual costs of pain-related healthcare, litigation, and compensation are estimated at $\$ 100$ billion in the United States. ${ }^{10} \mathrm{~A}$ paradox in the pharmacoeconomics of pain is that costs have been identified as a potential barrier to effective pain management, ${ }^{11}$ yet suboptimal pain management has been shown to increase overall 
healthcare costs. ${ }^{12}$ On the other hand, there has been a growing awareness that despite the increased costs of controlled-release (CR) opioids, their use may dramatically decrease long-term patient costs. ${ }^{13}$ However, achieving clinically and cost-effective outcomes is contingent on the physician recognizing and overcoming important barriers to successful pain management. In subsequent sections, a number of important factors and approaches are considered that may help guide primary care physicians and family practitioners when considering opioid medications for patients reporting moderate to severe pain.

\section{Factors Influencing Treatment Success or Failure \\ Patient and Physician Fears}

Patients may be reluctant to take opioid analgesics for various reasons, including fears of addiction. ${ }^{14}$ Clinicians can help patients with these fears by acknowledging that although the risk is real, the risk seems low for the large majority of patients taking opioids. In a study of more than 100 patients taking opioids for chronic noncancer pain for a mean duration of 14 months, the rate of addiction was $2.8 \% .{ }^{15}$ More recently, opioid use and stability of daily dose were studied in an analysis of pharmacy records of 152 orthopedic spine clinic patients. ${ }^{16}$ Persistent escalations of the mean daily dose were observed in 11 patients $(7.2 \%)$ during the 3 -year study period; 3 of these cases $(2.0 \%)$ could not be attributed to worsening pain and were accompanied by abuse behaviors. Addiction potential was also studied prospectively in a trial of 10 patients with chronic noncancer pain. ${ }^{17}$ In this pilot study, morphine was substituted for placebo for 60-hour periods to evaluate the effects of abstinence versus those of continued use. Three of the 10 patients $(30 \%)$ experienced opioid withdrawal symptoms, but no patients reported a craving for morphine, a compulsion to take morphine, or other indicators of psychological dependence. Moreover, although pain scores increased during the abstinence period, they remained below baseline levels. The results of these studies are limited by the small sample sizes, lack of a control group in all but the pilot study, and recall bias inherent in the retrospective analysis. However, the observed addiction rates of $\leq 2.8 \%$ suggest that, with appropriate man- agement, the potential for addiction to opioids is low during long-term treatment of noncancer pain.

Physician concern regarding opioid misuse remains perhaps the most significant barrier to the optimal use of opioids in patients with chronic, noncancer pain. This includes the risk of addiction in patients, drug diversion by patients (or members of their household) for nonpain purposes, the fear of attracting substance abusers to one's practice, and fear of legal/regulatory authorities. ${ }^{18}$

\section{Risk Management and Strategies to Minimize Abuse}

Initially, it was hoped that long-acting opioid formulations would eliminate the potential for abuse, but this has not proven to be the case. The liability of sustained-release preparations is that an entire 12-hour to 24-hour dose may be diverted and rapidly administered, leading to toxicity. ${ }^{19}$ Furthermore, the problem of abuse is not limited to oral formulations. A recent report described 10 overdose cases that were attributed to abuse of fentanyl transdermal patches. ${ }^{20}$ Another report describes 4 cases of fatal intravenous (IV) fentanyl abuse that involved extraction of fentanyl from transdermal patches. $^{21}$

Although drug diversion and abuse is a reality, it should not prevent the legitimate use of opioids in the treatment of pain. ${ }^{5}$ Risk management programs are being developed to identify potential abusers and provide guidelines for the management of patients to avoid or identify situations in which drug diversion may occur..$^{5}$ These programs are designed to address the concerns that physicians have about prescribing controlled substances., ${ }^{3,22-27}$ They include physician education, opioid dosing agreements, multimodal analgesia, urine screening, pharmacy monitoring of multiple opioid prescriptions, and detailed guidelines that help clinicians oversee every aspect of the use of opioids in a patient with chronic pain (Table 1) (Strength of Recommendation Taxonomy [SORT] level 3). ${ }^{18,28}$ Appropriate selection of candidates for chronic opioid therapy may help reduce the potential for misuse. In general, candidates for long-term opioid therapy are those who have tried nonopioid treatments without success and in whom there is no history of substance abuse or diversion. To reduce the risk of opioid misuse, it is helpful to anticipate situations that facilitate such behavior. Because many of the hazards associated with opioid prescribing are increased by a lack of familiarity with 


\begin{tabular}{|c|c|}
\hline Do & Don’t \\
\hline $\begin{array}{l}\text { Consider opioids only after all other reasonable attempts at } \\
\text { analgesia have failed }\end{array}$ & $\begin{array}{l}\text { Forget to evaluate patients (ie, history and physical } \\
\text { examination) }\end{array}$ \\
\hline \multirow{2}{*}{$\begin{array}{l}\text { Recognize that a history of substance abuse, severe character } \\
\text { pathology, and chaotic home environment are } \\
\text { contraindications }\end{array}$} & Initiate treatment without first establishing a diagnosis \\
\hline & $\begin{array}{l}\text { Forget to obtain outside medical records or to talk with } \\
\text { previous practitioners (any verification at all) }\end{array}$ \\
\hline $\begin{array}{l}\text { Ensure that the primary responsibility for treatment is } \\
\text { assumed by a single practitioner }\end{array}$ & $\begin{array}{l}\text { Prescribe treatment without establishing specific goals (ie, } \\
\text { reduction in pain, improvement in function) }\end{array}$ \\
\hline $\begin{array}{l}\text { Obtain informed consent from the patient before initiating } \\
\text { therapy }\end{array}$ & $\begin{array}{l}\text { Fail to screen for addictive potential and monitor patient } \\
\text { through treatment }\end{array}$ \\
\hline Prescribe doses on an around-the-clock basis & \multirow{2}{*}{$\begin{array}{l}\text { Fail to document the diagnosis, treatment plan, goals for } \\
\text { treatment, continuing need for medication, and laboratory } \\
\text { results }\end{array}$} \\
\hline $\begin{array}{l}\text { Reassess if failure to achieve at least partial analgesia at } \\
\text { relatively low initial doses in the nontolerant patient }\end{array}$ & \\
\hline Emphasize gains in physical and social function & Fail to understand what drug testing can and cannot tell you \\
\hline $\begin{array}{l}\text { Permit patients to transiently escalate dose on days of } \\
\text { increased pain }\end{array}$ & $\begin{array}{l}\text { Deviate from the 'contract' (ie, misbehavior is never addressed } \\
\text { either verbally or written) }\end{array}$ \\
\hline $\begin{array}{l}\text { See patients and prescribe drugs at least monthly, at least in } \\
\text { the initial phases of treatment }\end{array}$ & Accept blindly whatever is said by the patient \\
\hline $\begin{array}{l}\text { the initial phases of treatment } \\
\text { Manage exacerbations of pain in the hospital, where dose } \\
\text { escalation can be observed and the dose returned to } \\
\text { baseline }\end{array}$ & \multirow[t]{5}{*}{$\begin{array}{l}\text { Attempt to bully law enforcement or regulatory agents, or } \\
\text { assume an arrogant 'I-know-best' attitude when confronted } \\
\text { by them }\end{array}$} \\
\hline $\begin{array}{l}\text { Assess patients for evidence of drug hoarding, acquisition of } \\
\text { drugs, uncontrolled dose escalation, or other aberrant } \\
\text { behaviors }\end{array}$ & \\
\hline $\begin{array}{l}\text { Incorporate comfort, side effects, functional status, and } \\
\text { existence of aberrant drug-related behaviors into pain } \\
\text { assessment at each visit }\end{array}$ & \\
\hline $\begin{array}{l}\text { Consider use of self-reporting instruments, an example of } \\
\text { which is shown in Table } 2\end{array}$ & \\
\hline $\begin{array}{l}\text { Remember that documentation is essential and should address } \\
\text { all elements of the visit assessment }\end{array}$ & \\
\hline
\end{tabular}

Adapted with permission from Portenoy ${ }^{28}$ and Gallagher. ${ }^{18}$

the patient, primary care physicians may be better able to avoid some of these hazards. ${ }^{18}$

Several recent efforts have focused on tools that aid in assessing addiction risks. For example, a 24-item assessment tool known as the Screener and Opioid Assessment for Patients with Pain (SOAPP) was developed and validated specifically for use in patients with chronic noncancer pain to predict the possibility of aberrant drug behaviors. ${ }^{25}$ Concept areas incorporated in the SOAPP include neurobiologic need for medicine, medication-related behaviors, antisocial behaviors and history, substance abuse history, psychiatric history, psychosocial problems, doctor-patient relationship, and personal care and lifestyle issues. Specific items are listed in Table 2. Other screening tools developed for patients with chronic pain include the 26-item Pain Medication Questionnaire ${ }^{29}$ and the 14-item Screening Tool for Addiction Risk. ${ }^{26}$

\section{Accurately Assessing Pain}

Clinicians face unique challenges in the management of noncancer pain. In practice settings, pain can be difficult to assess, measure, and interpret. In addition, patients may underreport the amount of pain they experience or fail to report inadequate relief. Numerous tools have been developed and validated to assist the clinician in the assessment of pain. Unidimensional tools measure only pain intensity but are simple to administer and can be understood by most patients. ${ }^{9}$ Examples include the numeric rating scale (NRS), the verbal rating scale (VRS), and the faces pain-rating scale (FPRS); all are simple, reproducible, able to measure small changes in pain intensity, and useful in patients of different cultural backgrounds. The NRS is a more sensitive indicator of pain intensity than the VRS but can be difficult to use in cognitively impaired persons. The FPRS can be used effectively in small 


\begin{tabular}{|c|c|}
\hline Item & Concept Domain \\
\hline How often do you feel that your pain is out of control? & Neurobiologic need for medicine \\
\hline How often have you felt a need for higher doses of medication to treat your pain? & Neurobiologic need for medicine \\
\hline How often have you felt a craving for medication? & Neurobiologic need for medicine \\
\hline How often do you take more medication than you are supposed to? & Medication-related behaviors \\
\hline How often have you taken medication other than the way that it was prescribed? & Medication-related behaviors \\
\hline How often have your medications been lost or stolen? & Medication-related behaviors \\
\hline How often have others expressed concern over your use of medication? & Medication-related behaviors \\
\hline How often has more than one doctor prescribed pain medication for you at the same time? & Antisocial behaviors \\
\hline How often, in your lifetime, have you had legal problems or been arrested? & Antisocial behaviors \\
\hline How often do you smoke a cigarette within an hour after you wake up? & Substance abuse history \\
\hline $\begin{array}{l}\text { How often have any of your family members, including parents and grandparents, had a } \\
\text { problem with alcohol or drugs? }\end{array}$ & Substance abuse history \\
\hline How often have any of your close friends had a problem with alcohol or drugs? & Substance abuse history \\
\hline How often have others suggested that you have a drug or alcohol problem? & Substance abuse history \\
\hline How often have you attended an AA or NA meeting? & Substance abuse history \\
\hline How often have you been treated for an alcohol or drug problem? & Substance abuse history \\
\hline $\begin{array}{l}\text { How often have you used illegal drugs (for example, marijuana, cocaine, etc.) in the past } \\
5 \text { years? }\end{array}$ & Substance abuse history \\
\hline How often do you have mood swings? & Psychiatric history \\
\hline How often have you been seen by a psychiatrist or a mental health counselor? & Psychiatric history \\
\hline How often do you do things that you later regret? & Psychosocial problems \\
\hline How often has your family been supportive and encouraging? & Psychosocial problems \\
\hline How often have others told you that you have a bad temper? & Psychosocial problems \\
\hline $\begin{array}{l}\text { How often have you had a problem getting along with the doctors who prescribed your } \\
\text { medicines? }\end{array}$ & Doctor-patient relationship \\
\hline How often have you been asked to give a urine screen for substance abuse? & Doctor-patient relationship \\
\hline Compared with other people, how often have you been in a car accident? & Personal care/lifestyle \\
\hline
\end{tabular}

AA, Alcoholic's Anonymous; NA, Narcotics Anonymous.

Adapted with permission from Butler et al. ${ }^{25}$

children and developmentally disabled adults but requires careful instruction and may be affected by visual impairment. Multidimensional tools measure several aspects of pain, including intensity, frequency, and impact on quality of life and may give a more reliable assessment of the patient's overall pain syndrome. ${ }^{9}$ Examples include the McGill Pain Questionnaire and the Brief Pain Inventory. Multidimensional tools take more time than unidimensional tools to complete, require careful instruction, and often require expert interpretation; hence, they may be less practical for the primary care office.

\section{Opioids in Clinical Practice Initiating Opioid Therapy, Dosing, and Routes}

To initiate a patient on opioid therapy, the clinician should select a dosage and frequency based on the intensity of the patient's pain, the presence of co- morbid medical conditions, any concomitant therapy, and any previous opioid exposure (SORT level C). ${ }^{30,31}$ Dosing and frequency recommendations should also be consistent with the manufacturer's prescribing information. Short-acting agents (eg, morphine immediate release [IR], hydrocodone IR, hydromorphone IR, oxycodone IR, oxymorphone IR, and transmucosal fentanyl) may be favored initially because they are easier to titrate than longacting agents (eg, morphine CR, oxycodone extended release [ER], oxymorphone ER, and transdermal fentanyl). Short-acting opioids are characterized by a rapid rise and fall in serum opioid levels, whereas serum levels of long-acting opioids increase slowly to therapeutic levels, remain there for an extended period, and then decline slowly. ${ }^{23}$ Thus, after a stable dose is achieved with a short-acting agent, it may be preferable to convert to a longer-acting formulation of the same 
opioid. The difference in long- and short-acting formulations is appreciated by comparison of the ER and IR pharmacokinetic curves of oxymorphone (Figure 1). ${ }^{32,33}$ Longer-acting formulations provide patient convenience, improved compliance, and uniformity of effect. Whether longeracting formulations offer reduced adverse event (AE) profiles is a matter of debate, with different studies drawing opposing conclusions. In principle, the use of a long-acting formulation producing steady-state concentration with fewer peak-andtrough events predicts a reduction in AEs such as nausea or somnolence. Several trials comparing long-acting formulations with IR formulations of the same opioid have shown that the incidence of AEs is similar between the formulations. ${ }^{34-36}$ However, patient compliance with prescribed dosing regimens may be greater in these controlled settings. In general clinical practice, the less convenient, shorter-acting formulations may engender reduced compliance, more dosing errors, and more frequent AEs.

In patients being treated with long-acting agents, short-acting opioids can also be provided as rescue medication. Because of considerable interpatient variability in opioid responsiveness, it may take several trials of opioid regimens to find the drug that provides the best balance between pain relief and AEs (SORT level C). ${ }^{37}$

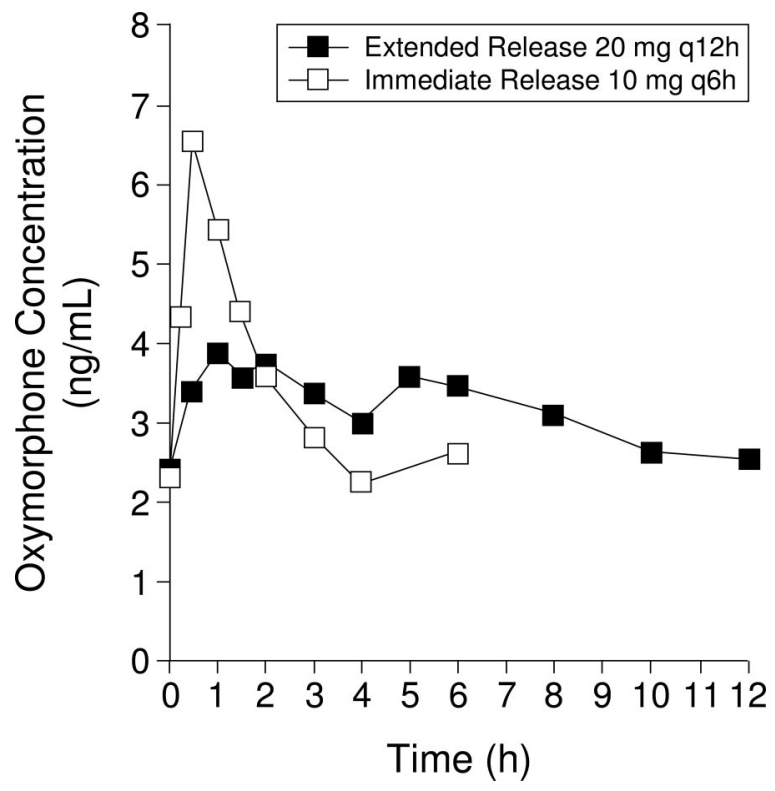

Figure 1. Mean steady-state plasma concentration of oxymorphone immediate release $10 \mathrm{mg}$ and oxymorphone extended release $20 \mathrm{mg} .{ }^{32,33}$
Neuraxial opioid therapy (intrathecal or epidural) for chronic cancer and noncancer pain has become an increasingly used therapeutic modality in recent years. In general, patients may be considered candidates for neuraxial opioid therapy if conventional opioid therapy is ineffective or not tolerated, and less invasive strategies for managing difficult-to-treat patients (eg, opioid rotation) have failed (SORT level A). ${ }^{38}$

Once therapy has been initiated, the dose should be titrated to a stable dose that provides effective analgesia throughout the dosing period with minimal need for rescue medication (SORT level C). ${ }^{30}$ It is important to recognize that there is no single optimal or maximal dose of an opioid analgesic drug; the effective management of chronic pain requires that adequate analgesia be maintained with the minimal number of doses per day. Data suggest that to achieve effective analgesia, a significant number of patients with chronic pain require more frequent dosing of sustained-release opioid preparations than that recommended by the manufacturer in published product information (SORT level 3). ${ }^{39-41}$

The need for increased dosing frequency may be explained by several factors, including type of pain, adjuvant opioid use, presence of comorbidities, and psychosocial factors. However, for many patients taking a CR opioid (including transdermal fentanyl, sustained-release morphine, and sustained-release oxycodone), end-of-dose failure was the reason for exceeding the manufacturer's recommended dosing frequency. ${ }^{40}$ In addition, some opioid formulations may have pharmacodynamic or pharmacokinetic profiles that are altered by concurrent medications. ${ }^{42,43}$ Genetic factors also probably influence pain perception and analgesia. ${ }^{44}$ These factors may not only contribute to alterations in the drug dosing interval but may affect whether a patient achieves a satisfactory outcome at all. Patient responses to opioids are highly variable. As detailed in a subsequent section, this clinical heterogeneity has driven the development of opioid rotation, because patients who respond poorly to one opioid frequently achieve a favorable response by switching to another. ${ }^{37,39}$

The decision to use strong opioids for the management of chronic pain is influenced by numerous factors, including the specific pain diagnosis, the severity of the pain, whether or not the patient has a history of drug abuse or diversion, the physician's 
type of practice, the regulatory climate of the physician's community, the acceptance of opioid analgesia in the physician's community, and the availability of pain specialists in the physician's community. ${ }^{45}$ As more primary care physicians and family practitioners prescribe strong opioids for the management of chronic and moderate to severe pain, the questions of how to monitor adherence to the therapeutic regimen and when to refer a patient to a pain specialist have become important topics. Monitoring adherence with chronic opioid therapy is difficult and complicated by psychological, societal, and legal issues. ${ }^{46}$ Periodic urine or plasma monitoring may facilitate adherence monitoring in patients with behavioral issues or a history of poor adherence to prescribed drug therapy. ${ }^{47}$ In general, referral to a pain specialist or pain center is appropriate when the clinician has exceeded his or her comfort level with the dose of opioids prescribed or the patient's ability to adhere to the prescribed regimen, has been unable to achieve adequate pain control despite increasing the dose of opioids, or has been unable to manage the patient's pain with different opioids (SORT level C). ${ }^{30}$

\section{Managing Opioid-related Adverse Events}

In opioid-naive patients, most opioid-related AEs are transient and tend to resolve with ongoing treatment. Common opioid-related AEs include constipation, nausea, vomiting, sedation, and pruritus. Most opioid-related AEs are dose dependent, which is why it is important to initiate therapy with the lowest effective dose. Some opioid-related AEs are often treated symptomatically (eg, by prescribing an antiemetic for nausea or a laxative for constipation); others, such as sedation and pruritus, are typically addressed by decreasing the opioid dose rather than by treating the symptom. ${ }^{48}$ In addition to dose reductions, other strategies that can be used to minimize opioid-related AEs include changing the route of administration and switching to a different opioid. ${ }^{49}$

Clinicians also may be concerned about increasing the dose of opioids to offset the effects of tolerance. Tolerance to opioids can arise as a result of pharmacokinetic adaptations such as increased drug clearance or pharmacodynamic adaptations such as reduced responsiveness of opioid receptors to the opioid. ${ }^{49}$ Increased experience in the treatment of chronic pain has shown that higher doses of opioids, may produce hyperalgesic effects. ${ }^{50} \mathrm{It}$ is possible that higher doses of opioids stimulate the central nervous system by mechanisms different from those used to inhibit nociception with lower doses of opioids. ${ }^{51,52}$ Additional research in this area may help in the development of approaches that maximize the analgesic benefits of opioids whereas minimizing long-term effects. Until such time, the clinician should consider alternate procedures to break the cycle of tolerance, including opioid rotation and multimodal analgesia.

\section{Multimodal Analgesia}

Use of multimodal analgesia also has become more widely recognized with the growing use of adjuncts such as nonsteroidal anti-inflammatory drugs (NSAIDs) and local anesthetics, and adjuvants such as anticonvulsants and tricyclic antidepressants. Use of adjunctive or adjuvant therapy may reduce opioid requirements as much as $25 \%$ to $50 \%$ and provide important benefits, such as reduced AEs and delayed development of tolerance and hyperalgesia. ${ }^{53}$ Because multiple mechanisms may be involved with opioid tolerance, the use of adjunctive or adjuvant therapies to target processes not affected by the opioid may increase overall treatment effectiveness without increasing the opioid dose. ${ }^{50}$ It should be noted, however, that use of these agents also may increase the risk of AEs from drugdrug interactions. Care must be taken in choosing opioids and concomitant agents with a low potential for causing drug interactions. The ability to successfully use drug combinations helps underscore that our understanding of the neurologic aspects of pain has increased dramatically. ${ }^{54-56}$

\section{Managing Polypharmacy}

When prescribing or recommending opioid therapy, it is important to consider the possibility of drug-drug interactions. The pharmacodynamic or pharmacokinetic profiles of many medications, including opioids, may be altered by other medications that are being taken concurrently. Most marketed drugs are metabolized in various ways by the cytochrome P450 (CYP450) system. ${ }^{57}$ In the case of most opioids, metabolism occurs primarily through the CYP3A4 and/or CYP2D6 pathways. The use of concomitant medications interacting with CYP3A4 or CYP2D6 (Table 3) may affect the plasma levels of the opioid or of other concomitant medications, resulting in reduced analgesia or AEs. ${ }^{57,58}$ For example, phenothiazines can reduce 
Table 3. Opioids and Other Medications Metabolized by CYP2D6 and CYP3A4 Enzymes

\begin{tabular}{|c|c|c|}
\hline Enzymes & Opioids & $\begin{array}{c}\text { Popular Medications/ } \\
\text { Substrates }\end{array}$ \\
\hline CYP2D6 & $\begin{array}{l}\text { Codeine } \\
\text { Dextromethorphan } \\
\text { Dihydrocodeine } \\
\text { Oxycodone } \\
\text { Tramadol }\end{array}$ & $\begin{array}{l}\text { Carvedilol } \\
\text { Propafenone } \\
\text { Amitriptyline } \\
\text { Paroxetine } \\
\text { Risperidone } \\
\text { Thioridazine } \\
\text { Fluoxetine } \\
\text { Lidocaine } \\
\text { Nortriptyline } \\
\text { Propranolol } \\
\text { Tamoxifen } \\
\text { Venlafaxine }\end{array}$ \\
\hline CYP3A4 & $\begin{array}{l}\text { Buprenorphine } \\
\text { Fentanyl } \\
\text { Methadone } \\
\text { Oxycodone }\end{array}$ & $\begin{array}{l}\text { Clarithromycin } \\
\text { Erythromycin } \\
\text { Alprazolam } \\
\text { Cyclosporine } \\
\text { Chlorpheniramine } \\
\text { Diltiazem } \\
\text { Lovastatin } \\
\text { Hydrocortisone } \\
\text { Buspirone } \\
\text { Caffeine } \\
\text { Nifedipine } \\
\text { Verapamil } \\
\text { Diazepam }\end{array}$ \\
\hline
\end{tabular}

Data from Flockhart ${ }^{57}$ and Lalovic et al. ${ }^{58}$

the effect of oral anticoagulants, and thiazide diuretics can accentuate the orthostatic hypotension that may occur with phenothiazines; hence, prochlorperazine should be used with caution in patients taking other phenothiazines, oral anticoagulants, or thiazide diuretics. ${ }^{59}$ The antiemetic, ondansetron is metabolized by the CYP450 enzymes CYP3A4, CYP2D6, and CYP1A2; hence, it should be used with caution in patients taking drugs metabolized by these enzymes (eg, phenytoin, carbamazepine, and rifampicin). ${ }^{60}$

Although there is currently little evidence to indicate that metabolic drug interactions between opioids and other medications are compromising patient safety, there is considerable evidence that many patients fail to achieve adequate analgesia with a given opioid, and drug interactions are a promising area for future research on this phenomenon. For example, codeine is a prodrug that must be metabolized to morphine by CYP2D6 to achieve analgesic effect. Because of genetic differences, this enzyme is very polymorphic so that some persons are rapid metabolizers whereas others are very poor metabolizers of certain drugs such as codeine. ${ }^{61}$ Thus, poor metabolizers who take codeine with other drugs metabolized by CYP2D6 may be at an increased risk for analgesic failure.

Notably absent from the table are morphine, which is metabolized principally by glucuronidation, ${ }^{62}$ and oxymorphone. Available data indicate that oral oxymorphone neither inhibits nor induces CYP450 metabolic pathways, nor is it significantly metabolized by CYP450 enzymes. ${ }^{40}$ These properties may offer clinical advantages to patients requiring multiple medications.

\section{Understanding Variable Patient Responses}

Lack of understanding about how opioids work may represent another barrier facing clinicians who manage patients with chronic nonmalignant pain. The identification of multiple opioid-receptor subtypes has facilitated the understanding of nociceptive, antinociceptive, and non-nociceptive effects of opioids. Various receptor subtypes play different roles in mediating the effects of opioids: $\mu$ is thought to mediate analgesia, $\kappa$ is associated with dysphoria and sedation, and $\delta$ elicits dysphoria. ${ }^{63,64}$ Opioids can act on different receptors, and individual receptor profiles may influence the degree of analgesia attainable and the occurrence of opioidrelated AEs. ${ }^{65}$ In addition, there are differences between people not only in responses to pain but also in levels of $\mu$-opioid receptor expression and responses to different opioids. For example, oxymorphone exhibits greater specificity for the $\mu$-opioid receptor, ${ }^{63}$ whereas oxycodone may exert some of its antinociceptive effect through the $\kappa$-opioid receptor. ${ }^{66}$ Genetic heterogeneity in the nociceptive pathways and drug metabolic pathways may also contribute to the wide range of patient responses to analgesic medications, including opioids. $^{44,61}$ At the present time, it is not generally possible to predict which patients will respond best to a particular drug. If the clinician has been unable to achieve adequate pain control with acceptable adverse effects, an alternative opioid medication should be considered.

\section{Opioid Rotation}

Opioid rotation has been shown to be an effective strategy for managing AEs or inadequate analgesia 
in patients taking opioids for long periods, and some physicians use this technique to optimize pain control in patients with complex or therapeutically challenging pain states. Studies show that opioid rotation has been effective in patients with noncancer pain. ${ }^{39,67}$ The success of rotation may be partly because of the effects of different opioid receptor subtypes. For example, female patients prescribed pure $\mu$ agonists may benefit from exposure to opioids that cross-react with $\kappa$ receptors. ${ }^{68}$

When opioid rotation is performed for patients with adequate pain relief but unacceptable AEs, the starting dose of the new opioid should be reduced $50 \%$ to $75 \%$ of the equianalgesic dose of the old opioid (SORT level 3). ${ }^{69}$ For patients with poor pain control and unacceptable AEs, the starting dose of the new drug can usually be $75 \%$ to $100 \%$ of the equianalgesic dose of the old drug (SORT level 3). ${ }^{69}$ Use of a standard equianalgesic dose table (an example of which is shown in Table 4) may facilitate opioid conversion; however, it is important to note that there is wide interpatient variability in the response to different opioids, ${ }^{70}$ and the doses shown in many standard equianalgesic dose tables may not be accurate in patients who have developed tolerance or have been taking opioids for long periods of time.

When opioid rotation is used, patients should be monitored closely to assess the adequacy of pain relief as well as the effect on opioid-related AEs. As with any opioid regimen, subsequent dose adjustments will probably be necessary. Use of opioid rotation requires familiarity with a range of opioids and with the use of equianalgesic dose tables. However, it is also important to consider that the evidence to support dose ratios in equianalgesic tables refers largely to the context of single-dose administration; they may not be completely accurate in cases of chronic opioid administration. ${ }^{50,70}$

Studies of patients with chronic cancer or noncancer pain have shown that many patients must switch opioid medications at least once, and sometimes as many as 3 to 4 times, before achieving effective analgesia with tolerable AEs. ${ }^{37,39}$ In such cases, the availability of multiple opioid analgesics is clearly crucial to achieving clinically satisfactory outcomes, and the development of new opioids or new formulations such as oxymorphone ER and IR, and morphine sulfate ER would provide new options.

\section{New Medications and Formulations}

As the use of opioids continues to expand, many issues and challenges regarding their use require attention. Among the many areas that need additional investigation are determining sufficient dosing for adequate analgesia, minimizing drug interactions, addressing highly variable patient responses, and minimizing drug abuse. It is hoped that new technology or knowledge will lead to formulations that will eliminate the potential for abuse. Other research is aimed at reducing tolerance, receptor downregulation, and antianalgesic effects of high-dose opioids (methadone, dextromethorphan, naltrexone), with the goals of improv-

Table 4. Dose Administration Data for Commonly Used Opioid Analgesics

\begin{tabular}{|c|c|c|c|c|}
\hline \multirow[b]{2}{*}{ Drug } & \multirow{2}{*}{$\begin{array}{c}\text { Approximate } \\
\text { Equianalgesic } \\
\text { Oral Dose }\end{array}$} & \multirow{2}{*}{$\begin{array}{c}\text { Approximate } \\
\text { Equianalgesic } \\
\text { Parenteral Dose }\end{array}$} & \multicolumn{2}{|c|}{$\begin{array}{l}\text { Recommended Starting Dose } \\
\text { (Adults }>50 \mathrm{~kg} \text { Body Weight) }\end{array}$} \\
\hline & & & Oral & Parenteral \\
\hline Morphine & $\begin{array}{l}\text { 20-60 mg/day initial starting } \\
\text { dose; then } 30 \mathrm{mg} \mathrm{q} 3-\mathrm{h} \text { (IR) }\end{array}$ & $10 \mathrm{mg} \mathrm{q} 3-4$ hours & $30 \mathrm{mg} \mathrm{q} 3-4$ hours* & $\begin{array}{l}10 \mathrm{mg} \mathrm{q} 3-4 \text { hours (use of } \\
\text { IV route is preferable) }\end{array}$ \\
\hline Fentanyl & & $0.1 \dagger$ & & \\
\hline Oxycodone & $30 \mathrm{mg} \mathrm{q} 3-4$ hours (IR) & NA & $10 \mathrm{mg} \mathrm{q} 3-4$ hours & NA \\
\hline Hydromorphone $\ddagger$ & $7.5 \mathrm{mg} \mathrm{q} 3-4$ hours & $1.5 \mathrm{mg} \mathrm{q} 3-4$ hours & $6 \mathrm{mg} \mathrm{q} 3-4$ hours & $1.5 \mathrm{mg} \mathrm{q} 3-4$ hours \\
\hline Methadone & $5-10 \mathrm{mg} \mathrm{q6}-8$ hours & $5-10 \mathrm{mg} \mathrm{q6}-8$ hours & $5-10 \mathrm{mg} \mathrm{q6}-8$ hours & $2.5-5 \mathrm{mg} \mathrm{q} 6-8$ hours \\
\hline
\end{tabular}

IR, immediate release; IV, intravenous; NA, not available.

* Starting dose of 20 to $60 \mathrm{mg} /$ day may be used to avoid adverse effects such as vomiting.

$\dagger$ Transdermal fentanyl $100 \mu \mathrm{g} / \mathrm{hr}$ is approximately equivalent to 2 to $4 \mathrm{mg} / \mathrm{hr}$ of $\mathrm{IV}$ morphine. A conversion factor for transdermal fentanyl that can be used for equianalgesic calculation is $17 \mu \mathrm{g} / \mathrm{hr}$. Roughly, the dose of transdermal fentanyl in $\mu \mathrm{g} / \mathrm{hr}$ is approximately one-half of the 24-hour dose of oral morphine.

₹ For morphine and hydromorphone, rectal administration is an alternate route for patients unable to take oral medication, but equianalgesic doses may differ from oral and parenteral doses because of pharmacokinetic differences.

Reprinted with permission from Nicholson. ${ }^{8}$ 
ing efficacy and decreasing tolerance and hyperalgesia.

Applications for opioids are also being developed in new areas such as neuropathic pain, which is pain caused by a peripheral or central nervous system deficit leading to alterations in sensory transmission that may continue even after healing has occurred. ${ }^{9,71}$ Until recently, it was believed that opioids were ineffective against neuropathic pain, but the results of several recent randomized controlled trials indicate that opioids can provide relief from neuropathic pain. ${ }^{72-74}$ Studies of the differing responses of persons to pain have generated new interest in determining whether men and women have the same responses to analgesics, and whether there are gender-based differences in opioid-activated endogenous pain-modulating circuits. ${ }^{68}$

Although it is hoped that basic laboratory and clinical science will help to drive the development of a new generation of analgesic agents, opioids such as fentanyl, morphine, and oxymorphone have been incorporated into new formulations that may help to advance the management of pain in acute and/or chronic settings.

For example, the fentanyl transdermal therapeutic system is a noninvasive delivery system for analgesic therapy. Its slow onset and offset is not suitable for acute pain, but the prolonged 72-hour duration is ideal for chronic pain states in which the patient's pain is fairly stable. ${ }^{75}$ For acute pain control through patient-controlled analgesia (PCA), fentanyl has been formulated in a patient-controlled transdermal system (PCTS) that uses a lowintensity current to electrophorese the drug onto the skin, where it diffuses into the local circulation. As with standard PCA, the patient self-administers each dose by pushing a button on the patch to activate the current. Such a system is clearly less invasive than standard PCA and may have fewer complications associated with its use. One randomized study showed that the system was comparable with standard IV PCA morphine for pain control, although it appears from the published data that patients consumed more opioid with the PCTS system than with IV PCA. ${ }^{76}$

In addition to these transdermal systems for chronic or acute pain, fentanyl has been formulated as oral transmucosal fentanyl citrate for the treatment of breakthrough pain. In one randomized placebo-controlled study, the drug seemed safe and efficacious as a rescue medication in patients re- ceiving other oral opioids as their principal pain medication. ${ }^{77}$

A new, capsular, once-daily, modified-release formulation of morphine sulfate was approved by the US Food and Drug Administration in early 2002. This morphine formulation is made up of 2 components-an IR component that rapidly achieves plateau morphine concentrations in plasma, and a sustained-release component that uses a spheroidal oral drug absorption system technology to maintain plasma morphine concentrations throughout the 24-hour dosing interval. The amount of morphine absorbed is similar to that of previous oral morphine formulations. ${ }^{78}$ In an openlabel trial, effectiveness and good tolerability was reported in cancer patients, and a randomized controlled trial reported improved quality of sleep compared with twice-daily morphine. ${ }^{79,80}$

An ER liposome injection of morphine sulfate is now available for single-dose administration by the epidural route, at the lumbar level, for the treatment of pain following major surgery. This formulation uses DepoFoam technology to provide extended drug release from a liposomal depot after a single-dose injection. ${ }^{81}$ Morphine sulfate ER liposome injection is administered before surgery or after clamping the umbilical cord during cesarean section. Randomized studies have shown that it provides analgesic efficacy superior to conventional epidural morphine. In general, improved efficacy was observed as either a significant reduction in patient pain and/or as a significant reduction in the use of postoperative supplemental opioids (eg, less IV PCA use). ${ }^{82,83}$ An additional advantage is that the use of a single injection obviates the need for epidural catheters or infusion pumps.

New formulations have also been developed for oxymorphone, a drug that has been used for many years in postanesthesia care units for rapid relief of severe surgical pain and on medical wards for chronic pain. ${ }^{84,85}$ Until recently, oxymorphone has been available primarily in IV and suppository forms, but now 2 new oral formulations of oxymorphone, ER and IR tablets, are being developed. In a long-term (12-month) study of patients with moderate to severe pain associated with osteoarthritis, effectiveness was reported with twice-daily dosing and no opioid rescue medication. ${ }^{86}$ In a randomized controlled trial performed in cancer patients, oxymorphone ER seemed to provide effective pain relief with twice-daily dosing; patients 
in this trial were permitted to take rescue medication but use was generally low (approximately 1 dose per day for breakthrough pain). ${ }^{87}$ Similar results were also reported in randomized controlled study of patients with chronic low back pain. ${ }^{88}$

These results are consistent with the proprietary sustained-release technology used to formulate oxymorphone ER. The formulation is based on an agglomerated hydrophilic matrix that allows the slow release of oxymorphone over a long period. The pharmacokinetic data and clinical efficacy results are potentially significant because reports for other chronic pain populations indicate that sustained-release forms of morphine and oxycodone are used 3 to 4 times daily, with an additional 3 to 4 doses of rescue medication. ${ }^{29,39,41}$ Clearly, additional studies are required to determine whether the 12-hour dosing observed in the clinical trials program with oxymorphone ER translates to these broader patient populations. Indeed, all the newer drug formulations reviewed in this section offer promising new options for pain management. Broader clinical experience with these formulations will determine how well these promises are kept.

\section{Conclusion}

Scientific knowledge about pain and opioids has increased significantly in the last 3 decades. The recognition of pain as the fifth vital sign has caused changes in the attitudes toward pain management, not only among clinicians but also within governmental and healthcare agencies. Pain is no longer considered to be merely a symptom; it is now recognized as a condition that needs to be managed and treated. Modalities such as neuraxial administration of opioids, PCA, transdermal therapeutic systems, and long-acting oral formulations provide a broader range of treatment options. Management techniques such as opioid rotation offer alternatives for increasing analgesic effectiveness or reducing AEs. The application of new knowledge and technology to existing opioids such as fentanyl, morphine, and oxymorphone provides the primary care physician and family practitioner with new tools in pain management. Despite the numerous advances, clinical practices and societal attitudes toward the use of opioids can be slow to change. Additional research advances coupled with ongoing physician and patient education will be required to address some of the remaining issues and barriers associated with effective pain management.

\section{References}

1. Adams NJ, Plane MB, Fleming MF, Mundt MP, Saunders LA, Stauffacher EA. Opioids and the treatment of chronic pain in a primary care sample. J Pain Symptom Manage 2001;22:791-6.

2. Federation of State Medical Boards of the United States I. Model guidelines for the use of controlled substances for the treatment of chronic pain. Available from: http://www.medsch.wisc.edu/painpolicy/ domestic/model.htm. Accessed December 8, 2004.

3. Gilson AM, Joranson DE. Controlled substances and pain management: changes in knowledge and attitudes of state medical regulators. J Pain Symptom Manage 2001;21:227-37.

4. Meldrum ML. A capsule history of pain management. JAMA 2003;290:2470-5.

5. Portenoy RK. Opioid therapy for chronic nonmalignant pain: a review of the critical issues. J Pain Symptom Manage 1996;11:203-17.

6. Portenoy RK, Foley KM. Chronic use of opioid analgesics in non-malignant pain: report of 38 cases. Pain 1986;25:171-86.

7. Martin TJ, Eisenach JC. Pharmacology of opioid and nonopioid analgesics in chronic pain states. J Pharmacol Exp Ther 2001;299:811-7.

8. Nicholson B. Responsible prescribing of opioids for the management of chronic pain. Drugs 2003;63:1732.

9. Brunton S. Approach to assessment and diagnosis of chronic pain. J Fam Pract 2004;53:S3-10.

10. National Institutes of Health. The NIH Guide: New directions in pain research I. Washington (DC): US Government Printing Office; 1998.

11. Mercadante S. Opioid rotation for cancer pain: rationale and clinical aspects. Cancer 1999;86:185666.

12. Chandler S, Payne R. Economics of unrelieved cancer pain. Am J Hosp Palliat Care 1998;15:223-6.

13. Abernethy AP, Samsa GP, Matchar DB. A clinical decision and economic analysis model of cancer pain management. Am J Manag Care 2003;9:651-64.

14. Twycross RG. Ethical and clinical aspects of pain treatment in cancer patients. Acta Anaesthesiol Scand 1982;26:83-90.

15. Cowan DT, Wilson-Barnett J, Griffiths P, Allan LG. A survey of chronic noncancer pain patients prescribed opioid analgesics. Pain Med 2003;4:340 51.

16. Mahowald ML, Singh JA, Majeski P. Opioid use by patients in an orthopedics spine clinic. Arthritis Rheum 2005;52:312-21.

17. Cowan DT, Wilson-Barnett J, Griffiths P, Vaughan DJ, Gondhia A, Allan LG. A randomized, doubleblind, placebo-controlled, cross-over pilot study to assess the effects of long-term opioid drug consumption and subsequent abstinence in chronic noncancer 
pain patients receiving controlled-release morphine. Pain Med 2005;6:113-21.

18. Gallagher R. Opioids in chronic pain management: navigating the clinical and regulatory challenges. $\mathrm{J}$ Fam Pract 2004;53:S23-32.

19. Charatan F. Time release analgesic causes fatal overdoses in United States. BMJ 2001;322:1143.

20. Kuhlman JJ Jr., McCaulley R, Valouch TJ, Behonick GS. Fentanyl use, misuse, and abuse: a summary of 23 postmortem cases. J Anal Toxicol 2003;27:499504.

21. Tharp AM, Winecker RE, Winston DC. Fatal intravenous fentanyl abuse: four cases involving extraction of fentanyl from transdermal patches. Am J Forensic Med Pathol 2004;25:178-81.

22. Gilson AM, Joranson DE. U.S. policies relevant to the prescribing of opioid analgesics for the treatment of pain in patients with addictive disease. Clin J Pain 2002;18:S91-8.

23. McCarberg BH, Barkin RL. Long-acting opioids for chronic pain: pharmacotherapeutic opportunities to enhance compliance, quality of life, and analgesia. Am J Ther 2001;8:181-6.

24. Bressler LR, Geraci MC, Schatz BS. Misperceptions and inadequate pain management in cancer patients. DICP 1991;25:1225-30.

25. Butler SF, Budman SH, Fernandez K, Jamison RN. Validation of a screener and opioid assessment measure for patients with chronic pain. Pain 2004;112: $65-75$.

26. Friedman R, Li V, Mehrotra D. Treating pain patients at risk: evaluation of a screening tool in opioidtreated pain patients with and without addiction. Pain Med 2003;4:182-5.

27. Adams LL, Gatchel RJ, Robinson RC, et al. Development of a self-report screening instrument for assessing potential opioid medication misuse in chronic pain patients. J Pain Symptom Manage 2004;27:440-59.

28. Portenoy RK. Opioid therapy for chronic nonmalignant pain: a review of critical issues. In: Fields HL, Liebeskind JC, editors. Pharmacological approaches to the treatment of chronic pain: new concepts and critical issues. Seattle (WA): IASP Publications; 1994. p. 247-87.

29. Adams D, Royal M, Jenson MG, et al. Retrospective assessment of frequency of dosing of sustained release opiate preparations. American Pain Society 21st Scientific Meeting, March 14-17, 2002. American Pain Society 2002 Abstract Database. Available from: http:// www.ampainsoc.org/cgi-bin/abstract2002/search.pl. Accessed September 15, 2004.

30. Wisconsin Medical Society. Guidelines for the assessment and management of chronic pain. WMJ 2004;103:13-42.

31. American Society of Anesthesiologists. A report by the American Society of Anesthesiologists Task
Force on pain management, chronic pain section. Anesthesiology 1997;86:995-1004.

32. Gimbel J, Ahdieh H. The efficacy and safety of oral immediate-release oxymorphone for postsurgical pain. Anesth Analg 2004;99:1472-7.

33. Adams MP, Ahdieh H. Pharmacokinetics and doseproportionality of oxymorphone extended release and its metabolites: results of a randomized crossover study. Pharmacotherapy 2004;24:468-76.

34. Parris WC, Johnson BW Jr., Croghan MK, et al. The use of controlled-release oxycodone for the treatment of chronic cancer pain: a randomized, double-blind study. J Pain Symptom Manage 1998; 16:205-11.

35. Stambaugh JE, Reder RF, Stambaugh MD, Stambaugh H, Davis M. Double-blind, randomized comparison of the analgesic and pharmacokinetic profiles of controlled- and immediate-release oral oxycodone in cancer pain patients. J Clin Pharmacol 2001;41: $500-6$.

36. Hale ME, Fleischmann R, Salzman R, et al. Efficacy and safety of controlled-release versus immediaterelease oxycodone: randomized, double-blind evaluation in patients with chronic back pain. Clin J Pain 1999; $15: 179-83$.

37. Cherny NJ, Chang V, Frager G, et al. Opioid pharmacotherapy in the management of cancer pain: a survey of strategies used by pain physicians for the selection of analgesic drugs and routes of administration. Cancer 1995;76:1283-93.

38. American Society of Anesthesiologists. Practice guidelines for cancer pain management. A report by the American Society of Anesthesiologists Task Force on pain management, cancer pain section. Anesthesiology 1996;84:1243-57.

39. Quang-Cantagrel ND, Wallace MS, Magnuson SK. Opioid substitution to improve the effectiveness of chronic noncancer pain control: a chart review. Anesth Analg 2000;90:933-7.

40. Adams M, Pieniaszek HJ Jr., Gammaitoni AR, Ahdieh H. Oxymorphone extended release does not affect CYP2C9 or CYP3A4 metabolic pathways. J Clin Pharmacol 2005;45:337-45.

41. Marcus DA, Glick RM. Sustained-release oxycodone dosing survey of chronic pain patients. Clin J Pain 2004;20:363-6.

42. Liston HL, Markowitz JS, DeVane CL. Drug glucuronidation in clinical psychopharmacology. J Clin Psychopharmacol 2001;21:500-15.

43. Lotsch J, Skarke C, Tegeder I, Geisslinger G. Drug interactions with patient-controlled analgesia. Clin Pharmacokinet 2002;41:31-57.

44. Mogil JS. The genetic mediation of individual differences in sensitivity to pain and its inhibition. Proc Natl Acad Sci USA 1999;96:7744-51.

45. Belgrade MJ. Opioids for chronic nonmalignant pain. Choosing suitable candidates for long-term therapy. Postgrad Med 1999;106:115-24. 
46. Fishman SM, Wilsey B, Yang J, Reisfield GM, Bandman TB, Borsook D. Adherence monitoring and drug surveillance in chronic opioid therapy. J Pain Symptom Manage 2000;20:293-307.

47. Katz NP, Sherburne S, Beach M, et al. Behavioral monitoring and urine toxicology testing in patients receiving long-term opioid therapy. Anesth Analg 2003;97:1097-102.

48. Pasero C, Portenoy RK, McCaffery M. Opioid analgesics. In: McCaffery M, Pasero C, editors. Pain clinical manual. St. Louis (MO): Mosby Inc.; 1999. p. 161-299.

49. Dews TE, Mekhail N. Safe use of opioids in chronic noncancer pain. Cleve Clin J Med 2004;71:897-904.

50. Cherny N, Ripamonti C, Pereira J, et al. Strategies to manage the adverse effects of oral morphine: an evidence-based report. J Clin Oncol 2001;19:254254.

51. Coluzzi PH, Schwartzberg L, Conroy JD, et al. Breakthrough cancer pain: a randomized trial comparing oral transmucosal fentanyl citrate (OTFC) and morphine sulfate immediate release (MSIR). Pain 2001;91:123-30.

52. Mercadante S, Ferrera P, Villari P, Arcuri E. Hyperalgesia: an emerging iatrogenic syndrome. J Pain Symptom Manage 2003;26:769-75.

53. Mercadante S. The use of anti-inflammatory drugs in cancer pain. Cancer Treat Rev 2001;27:51-61.

54. Caterina MJ, Julius D. The vanilloid receptor: a molecular gateway to the pain pathway. Annu Rev Neurosci 2001;24:487-517.

55. Ibrahim MM, Deng H, Zvonok A, et al. Activation of CB2 cannabinoid receptors by AM1241 inhibits experimental neuropathic pain: pain inhibition by receptors not present in the CNS. Proc Natl Acad Sci USA 2003;100:10529-33.

56. Wood JN, Heath MJ. Molecules that specify modality: mechanisms of nociception. J Pain 2000;1:1925 .

57. Flockhart DA. Cytochrome P450 drug interaction table. Indiana University School of Medicine. Available from: http://medicine.iupui.edu/flockhart/. Accessed September 15, 2004.

58. Lalovic B, Phillips B, Risler LL, Howald W, Shen DD. Quantitative contribution of CYP2D6 and CYP3A to oxycodone metabolism in human liver and intestinal microsomes. Drug Metab Dispos 2004;32:447-54.

59. Compazine (prochlorperazine) [full prescribing information]. Research Triangle Park (NC): GlaxoSmithKline; 2004.

60. Zofran (R) (ondansetron hydrochloride) [full prescribing information]. Research Triangle Park (NC): GlaxoSmithKline; 2004.

61. Evans DA, Mahgoub A, Sloan TP, Idle JR, Smith RL. A family and population study of the genetic polymorphism of debrisoquine oxidation in a white British population. J Med Genet 1980;17:102-5.
62. Yeh SY, Gorodetzky CW, Krebs HA. Isolation and identification of morphine-3 and 6-glucuronides, morphine 3,6 diglucuronide, morphine 3 ethereal sulfate, normorphine and normorphine 6-glucuronide as morphine metabolites in humans. J Pharm Sci 1977;66:1288-93.

63. Sinatra RS, Hyde NH, Harrison DM. Oxymorphone revisited. Semin Anesth 1988;7:209-15.

64. Pasternak GW. Pharmacological mechanisms of opioid analgesics. Clin Neuropharmacol 1993;16:1-18.

65. Uhl GR, Sora I, Wang Z. The mu opiate receptor as a candidate gene for pain: polymorphisms, variations in expression, nociception, and opiate responses. Proc Natl Acad Sci USA 1999;96:7752-5.

66. Ross FB, Smith MT. The intrinsic antinociceptive effects of oxycodone appear to be kappa-opioid receptor mediated. Pain 1997;73:151-7.

67. Grilo RM, Bertin P, Scotto di Fazano C, et al. Opioid rotation in the treatment of joint pain. A review of 67 cases. Joint Bone Spine 2002;69:491-4.

68. Gear RW, Miaskowski C, Gordon NC, Paul SM, Heller PH, Levine JD. Kappa-opioids produce significantly greater analgesia in women than in men. Nat Med 1996;2:1248-50.

69. Cherny NI, Portenoy RK. Cancer pain management. Current strategy. Cancer 1993;72:3393-415.

70. Galer BS, Coyle N, Pasternak GW, Portenoy RK. Individual variability in the response to different opioids: report of five cases. Pain 1992;49:87-91.

71. Fakata KL, Lipman AG. Pharmacotherapy for pain in rheumatologic conditions: the neuropathic component. Curr Pain Headache Rep 2003;7:197-205.

72. Gimbel JS, Richards P, Portenoy RK. Controlled-release oxycodone for pain in diabetic neuropathy: a randomized controlled trial. Neurology 2003;60:927-34.

73. Rowbotham MC, Twilling L, Davies PS, Reisner L, Taylor K, Mohr D. Oral opioid therapy for chronic peripheral and central neuropathic pain. $\mathrm{N}$ Engl J Med 2003;348:1223-32.

74. Watson CP, Babul N. Efficacy of oxycodone in neuropathic pain: a randomized trial in postherpetic neuralgia. Neurology 1998;50:1837-41.

75. Mystakidou K, Befon S, Kouskouni E, et al. From codeine to transdermal fentanyl for cancer pain control: a safety and efficacy clinical trial. Anticancer Res 2001;21:2225-30.

76. Viscusi ER, Reynolds L, Chung F, Atkinson LE, Khanna S. Patient-controlled transdermal fentanyl hydrochloride vs intravenous morphine pump for postoperative pain: a randomized controlled trial. JAMA 2004;291:1333-41.

77. Farrar JT, Cleary J, Rauck R, Busch M, Nordbrock E. Oral transmucosal fentanyl citrate: randomized, double-blinded, placebo-controlled trial for treatment of breakthrough pain in cancer patients. J Natl Cancer Inst 1998;90:611-6.

78. Avinza (morphone sulfate extended-release capsules) 
[full prescribing information]. San Diego (CA): Ligand Pharmaceuticals Incorporated; 2004.

79. Groves ES, Shelby SM, Schlosser L. Efficacy and safety of long-term, once-daily morphine sulfate extended-release capsules in camcer patients with chronic, moderate-to-severe pain. J Clin Oncol 2004;22:

80. Caldwell JR, Rapoport RJ, Davis JC, et al. Efficacy and safety of a once-daily morphine formulation in chronic, moderate-to-severe osteoarthritis pain: results from a randomized, placebo-controlled, double-blind trial and an open-label extension trial. J Pain Symptom Manage 2002;23:278-91.

81. Mantripragada S. A lipid based depot (DepoFoam technology) for sustained release drug delivery. Prog Lipid Res 2002;41:392-406.

82. Gambling D, Hughes T, Martin G, Horton W, Manvelian G. A comparison of Depodur, a novel, single-dose extended-release epidural morphine, with standard epidural morphine for pain relief after lower abdominal surgery. Anesth Analg 2005;100: 1065-74.

83. Carvalho B, Riley E, Cohen SE, et al. Single-dose, sustained-release epidural morphine in the manage- ment of postoperative pain after elective cesarean delivery: results of a multicenter randomized controlled study. Anesth Analg 2005;100:1150-8.

84. Sinatra RS, Lodge K, Sibert K, et al. A comparison of morphine, meperidine, and oxymorphone as utilized in patient-controlled analgesia following cesarean delivery. Anesthesiology 1989;70:585-90.

85. Sinatra RS, Harrison DM. A comparison of oxymorphone and fentanyl as narcotic supplements in general anesthesia. J Clin Anesth 1989;1:253-8.

86. McIlwain H, Ahdieh H. Safety, tolerability, and effectiveness of oxymorphone extended release for moderate to severe osteoarthritis pain: a one-year study. Am J Ther 2005;12:106-12.

87. Gabrail NY, Dvergsten C, Ahdieh H. Establishing the dosage equivalency of oxymorphone extended release and oxycodone controlled release in patients with cancer pain: a randomized controlled study. Curr Med Res Opin 2004;20:911-8.

88. Hale ME, Dvergsten C, Gimbel J. Efficacy and safety of oxymorphone extended release in chronic low back pain: results of a randomized, double-blind, placebo- and active-controlled phase III study. J Pain 2005;6:21-8. 